Article

\title{
Towards a Psychoanalytic Concept of Affective-Digital Labour
}

\author{
Jacob Johanssen \\ Communication and Media Research Institute (CAMRI), Faculty of Media, Arts and Design, University of Westminster, HA1 \\ 3TP Middlesex, UK; E-Mail: j.johanssen@westminster.ac.uk
}

Submitted: 15 February 2018 | Accepted: 7 May 2018 | Published: 11 September 2018

\begin{abstract}
This article draws on the argument that users on corporate social media conduct labour through the sharing of usergenerated content. Critical political economists argue that such acts contribute to value creation on social media and are therefore to be seen as labour. Following a brief introduction of this paradigm, I relate it to the notion of affective labour which has been popularised by the Marxist thinkers Michael Hardt and Antonio Negri. To them, affective labour (as a sub-category of immaterial labour) denotes embodied forms of labour that are about passion, well-being, feelings of ease, immaterial products and generally a kind of communicative relationality between individuals. I point to some problems with a lack of clarity in their conceptualisation of affective labour and argue that the Freudian model of affect can help in theorising affective labour further through a focus on social media. According to Freud, affect can be understood as a subjective, bodily experience which is in tension with the discursive and denotes a momentary feeling of bodily dispossession. In order to illustrate those points, I draw on some data from a research project which featured interviews with social media users who have facial disfigurements about their affective experiences online. The narratives attempt to turn embodied experiences into discourse.
\end{abstract}

\section{Keywords}

affective labour; digital labour; psychoanalysis; social media

\section{Issue}

This article is part of the issue "The Turn to Affect and Emotion in Media Studies", edited by Margreth Lünenborg and Tanja Maier (Free University Berlin, Germany).

(C) 2018 by the author; licensee Cogitatio (Lisbon, Portugal). This article is licensed under a Creative Commons Attribution 4.0 International License (CC BY).

\section{Introduction}

The field of digital labour studies has seen increasing publications in recent years that focus on framing user activity on social media as labour. Drawing on Marx's labour theory of value, scholars have argued that usergenerated content on commercial social media platforms, such as Facebook, Twitter, WeChat, or Weibo, is commodified and sold to advertisers. Users thus contribute to value being generated without receiving any monetary returns (e.g., Andrejevic, 2011, 2014; Comor, 2010; Dean, 2014; Fisher, 2012; Fuchs, 2012, 2014; Fuchs \& Sevignani, 2013; Terranova, 2000). Many have argued that such user labour is also affective labour because it is about communication, relationships, desires, embodiment, or in short about the circulation of affects online (Dean, 2014; Jarrett, 2015; Pybus, 2015). The works of
Michael Hardt and Antonio Negri $(2000,2004)$ on immaterial and affective labour have been of particular influence in this regard. This article engages with the above literature and critically discusses the lack of definitions of affective labour. The term affective labour is frequently evoked in the literature without clearly defining what is specifically affective about it. What is the nature of affective labour on social media?

In attempting to answer that question, I offer a psychoanalytic conceptualisation of affective labour by drawing on Freud's works on affect. Freud allows us to regard affective labour as a subjective process that is influenced by unconscious and relational dimensions as well as social forces. On social media, this means that affective labour occurs in relation to individuals' bodies and embodied states which are transformed into content. A psychoanalytic model of affective labour refers to al- 
ready embodied, affective bodily states that influence affective labour online. Such states can never be fully translated into user-generated content, because they consist of elements which are beyond the representational and discursive realm (such as bodily experiences). I illustrate this model with some examples from a recent research project on individuals with visible facial differences and their use of social media for raising awareness of their conditions. I discuss selected interview narratives which show attempts at talking about affective-digital labour on social media that are in relation to the individuals' bodies, and the difficulty of representing themselves and engaging with others online. Affect, then, may be seen as an attempt to articulate bodily experiences in user-generated content, but this attempt always remains somewhat incomplete.

\section{The Digital and Affective Labour Paradigms}

Critical political economy scholars have argued that the user activity on commercial social media platforms constitutes unpaid labour. This argument has been most notably advanced by Christian Fuchs $(2010,2012,2014)$ who draws on Karl Marx's labour theory of value and Dallas Smythe's (1981) notion of the audience commodity. For Marx, any activity that generates exchange value is considered labour (1976). Corporate social media companies such as YouTube, Facebook or Twitter (Ekman, 2012; Fisher, 2012) rely on users actively producing content which is then sold to advertisers to enable targeted advertising in return. Users do not receive a remuneration for this labour, but a free platform. As Fuchs elaborates:

Users spend time on corporate Internet platforms that are funded by targeted advertising capital accumulation models. The time spent on corporate platforms is the value created by their unpaid digital labour. Their digital labour creates social relations, profile data, user-generated content and transaction data (browsing behaviour) - a data commodity that is offered for sale by Internet corporations to advertising clients that can select certain user groups they want to target. The act of exploitation is already created by the circumstance that users create a data commodity, in which their online work time is objectified, and that they do not own this data themselves, but rather corporate Internet platforms with the help of terms of use and privacy policies acquire ownership of this data. Corporate Internet platforms offer the data commodity that is the result of Internet presumption activity for sale to advertisers. The value realization process, the transformation of value into profit, takes place when targeted users view the advertisement (pay per view) or click on it (pay per click). (Fuchs, 2014, pp. 95-96)

In that sense, the time spent producing user-generated content on social media platforms amounts to unpaid labour which contributes towards profit for the social media companies. There has been some critique of this argument and the digital labour debate is still ongoing (see, e.g., Jarrett, 2015, for an overview) but cannot be covered here in greater detail. Related to this notion of digital labour, is the concept of immaterial labour, of which affective labour is a subset, developed by the Marxist philosophers Maurizio Lazzarato (1996) and Michael Hardt and Antonio Negri $(2000,2004)$. They argue that within informational capitalism (Dean, 2014; Fuchs, 2008) there is a transformation in the workplace towards work which does not produce a material, tangible product but immaterial products. For example, call centre work, advertising creation, prostitution, acting, software design. Hardt and Negri define immaterial labour as labour "that creates immaterial products, such as knowledge, information, communication, a relationship, or an emotional response" (2004 p. 108). They note that there is an increasing drive for the labour process to become immaterial: "today labour and society have to informationalize, become intelligent, become communicative, become affective" (2004 p. 109). For Hardt and Negri, affective labour is a component, or sub-aspect, of immaterial labour. I follow and develop their definition in this article. It involves "the production and manipulation of affect and requires (virtual or actual) human contact, labour in the bodily mode...the labour is immaterial, even if it is corporeal and affective, in the sense that its products are intangible, a feeling of ease, well-being, satisfaction, excitement or passion" (2000, p. 292).

Examples of affective labour include software designers, web developers, waiters and waitresses, sex workers, academics, and service workers (Hearn, 2010, p. 63). However, Hardt and Negri never clearly define what they mean by affect (Lanoix, 2013) and their use of the term seems to be implicitly more about intellectual-based work rather than fully embodied work. There is a privilege of reason and rationality over the messiness of embodied labour (Ahmed, 2014, p. 206). It is not clear how the term affective labour considerably advances discussions or develops arguments that much earlier concepts, such as Hochschild's emotional labour (1983), could not have articulated already. While certain types of industries have increased significantly over the past decades (information service work, care work, creative industries jobs), the question poses itself: what is distinctly "affective" about such work?

Kylie Jarrett (2015) and others (e.g., Coté \& Pybus, 2011) have argued that social media use which is exploited is particularly affective. This affectivity is established through exchanges between a user, the platform interfaces and other users (e.g., in commenting on posts on Facebook, in re-tweeting on Twitter, in engaging in a discussion on Instagram). All of those examples are relational instances of the circulation of content. The more content circulates, the better for social media companies. Jodi Dean's work on communicative capitalism (2014) makes a similar argument. While Dean, who draws on 
Lacanian ideas, has made important points about the role of affect in communicative capitalism, she has not explored how it can be studied empirically through a focus on lived experiences of individuals. There is thus scope to develop this critical tradition further. Recently, a number of scholars have specifically connected the notion of affect with social media (Clough, 2013; GardeHansen \& Gorton, 2013; Johanssen, 2016; Karatzogianni \& Kuntsman, 2012; Paasonen, Hillis, \& Petit, 2015; Sampson, 2012). Paasonen et al. write that many forms of online user activity are about affect in a broader sense (e.g. reading news online, using Google, posting an update on social media). Such intense "affective investments" $(2015$, p. 7) show "articulations of desire, seduction, trust, and memory; sharp jolts of anger and interest; political passions; investments of time, labor, and financial capital; and the frictions and pleasures of archival practices" (2015, p. 1). Often, communication on social media is not "merely instrumental" (Paasonen et al., 2015, p. 10) and about goal-directed actions but also beyond rationality and conscious control. It is this idea of an intense form of embodied engagement with the Internet that makes affect a useful concept to work with when it comes to critically analysing social media use. Kylie Jarrett (2015) has similarly described social media use: "Rather than merely a site of disembodied rationality, the Internet is a site for physical arousal, heightened emotion and the cultivation and maintenance of rich social relationships" (p. 121).

However, perhaps due to affect's notorious slipperiness and messiness as a concept, the term is often used vaguely or contradictorily by different scholars. As noted, Paasonen et al. write of "affective attachments" on the Internet (2015, p. 1). Using social media may denote particular affective attachments or experiences, but what is specifically affective about them? In his work on Tumblr and its queer community, Alexander Cho (2015) has called affect "a moment of suspense, a shift, an attunement between entities" (p. 44). Veronika Tzankova (2015) has referred to networked affect, that is affective relationalities and communication online, as "a complex set of intensities associated with rational and nonrational modalities" (p. 62). Affect may "produce meanings that are only implicitly articulated in online discourse and representations" (Tzankova, 2015). The affect theorists Patricia Clough, Greg Goldberg, Rachel Schiff, Aaron Weeks and Craig Willse (2007) have defined affect as something that "is meant to address the becoming abstract, and therefore becoming subject to measure that which is seemingly disparate" (Clough et al., 2007, p. 62). Admittedly, I have taken such definitions out of context here, but they demonstrate the complexity and diversity of affect as a notion and its vagueness. I would like to offer a psychoanalytic, Freudian model of affect that seeks to clarify what affect means from a particular perspective. I would like to take this aspect of social media use as a form of unpaid, affective labour as a starting point in order to theorise it by drawing on Freud. Focussing on the inherent, rather than functional dimensions of affective labour on social media can add complexity to the concepts of affective / digital labour. Feminist scholars have made very important contributions to this debate by inserting care labour, reproductive labour, or feminised work back into the debate (Jarrett, 2015). There is scope to continue this kind of work. There are inherent problems with how Hardt and Negri $(2000,2004)$ use the term affective labour, because they do not really specify what is essentially affective about it or where the affectivity lies (see Johanssen, in press, for an extended discussion of this point), but I would like to focus here on the use of the term in relation to social media.

\section{Affect and Psychoanalysis}

Sigmund Freud (1981), in contrast to many affect theories which emphasise the transindividual, non-discursive qualities and floating state of affect, developed a model that regards affect as an embodied, subjective experience. For him, an affective experience is felt through the body by being affected by someone or something. For example, in response to something the subject may see on social media. An affective experience is momentary and transitory and constitutes a movement from the body towards the social, from the internal towards the external. In an affective experience, the affect moves and is, what Freud called, "discharged" (1981a) by the subject. An affective experience can either be pleasurable or unpleasurable. It is not experienced or named as a specific emotion. Instead, it is difficult for the individual to precisely explain how they have felt during an affective experience. Affect, for Freud, always designates a state of momentary bodily dispossession. The psychoanalyst Ruth Stein has offered a useful definition in this context:

\footnotetext{
"my body speaks itself to me"; when I am feeling, I possess my body, but at that same moment, the body is also its own speaker, and the three terms join together and link my possession ("my"), the object of this possession ("body"), and that which denies my possession ("it speaks" - and in that it is its own master, or speaker, thereby denying my possession of itself). (Stein, 1999, p. 127)
}

The body is experienced as "other" in such moments. Affect marks almost a degree of separation between the body and how the subject feels the body speaking itself. Such experiences can be reflected on afterwards. The individual cannot clearly define the affective qualities but tries to make sense of them through language (Johanssen, 2016). There is a sense of tension in trying to describe how an individual was affected by a particular bodily sensation. In that sense, affective experiences are situated in-between the discursive and the non-discursive (Green, 1999). The psychoanalytic conceptualisation of affect is particularly useful because it, in contrast to most affect theories in the humanities, ar- 
gues that "affect" designates a subjective, bodily experience that is felt rather than completely known by the individual. The Freudian affect model is beneficial for this project because it places an emphasis on a tension between discursive and bodily aspects of experiences. It therefore allowed to research affective experiences empirically through qualitative interviews. In the next section, I present some examples that assist in sketching out a model of affective labour on social media which is influenced by psychoanalysis.

\section{Affective Labour on Social Media: Raising Awareness of Facial Disfigurements}

The data presented in this section was gathered as part of a research project on the use of social media by people with facial disfigurements in the UK (https://sites.google.com/view/mediadisfigurement). In the qualitative interviews, individuals were encouraged to speak without too much intervention on the part of the interviewer. While some affect theories tend to move away from discourse-based methods and analyses, this project was specifically interested in giving people with facial disfigurements, who are often misrepresented in the media, a voice so that they could account for their own feelings and embodied experiences of using social media. Participants were also encouraged to talk about their life histories and general life experiences of living with disfigurements. It was thus hoped that through their narratives discursive attempts could emerge that illustrate affective experiences. Seven individuals were interviewed and, coincidentally, all presented a very professional use of social media which was aimed at raising awareness of facial disfigurements, at disrupting stereotypes and engaging with the wider public (Garrisi \& Johanssen, 2018; Johanssen \& Garrisi, 2017). From the outset, one could describe such forms of social media use as a kind of campaigning, or professionalised labour with specific goals in mind.

\subsection{Different Bodies on Social Media}

One research participant had sustained burns as a young infant. As she grew up, she was faced with a changing body, like all of us, but her burns would change throughout her life. She explained:

Like with burns where it doesn't grow, it just pulls and like normal skin grows and stretches, where burns doesn't, so and reconstructive surgery and it is altering an image that you already see in the mirror, so you may get used to a scar, you may get used to a burn but then you're having surgery and it may get altered and then you develop that kind of attachment to your original burns which is weird, so kinda like it's, I don't know how to explain it, it's kinda like, it just kinda knocks you for six, so it and it just makes you feel like a bit alien having this new burn, or this new scar, or this new skin graft, you're like "Oh what is this?", will that bother ya, that little skin graft, but not having burns since you are eighteen months that is really weird erm but like where it doesn't grow or stretch it may like leave, it might make, so for example, I can't explain it, can you see here? [Points to her arm]. (I3)

The quote suggests how her body was affected by a particular experience of living with burns. The narrative can be seen as an attempt to render the affective experiences associated with growing up with a particular bodily condition into language. The interviewee was not quite able to fully describe her embodied state: "I can't explain it", she said. Living with burns and a changing body was described by her in affective terms which stressed bodily functions and an embodied relatedness to being in the world, but she seemed not fully able to turn affective experiences into language. Such states were often described by the interviewees through bodily terms. Another interviewee specifically wondered about her usage of the word "disfigurement" and if it was an appropriate signifier for describing a bodily condition:

You know, I remember actually, you know, I didn't even really consider myself, or I had, the word disfigured, I didn't even attribute that word to myself until, like, until, I think it was on my last operation, so I would have been about 20-ish. I met my surgeon, and he said, "Oh yes, this..." He said a comment like, "Oh yes, this type of disfigurement blah, bah, blah." I was like, "Ah! I'm disfigured?" I was like, "Oh yes, of course I am." But I just always saw myself as wonky, or you know, I don't know, I just never. (I5)

The term "disfigured" possibly symbolised particular states of being for the participant and she was affected by a surgeon referring to her as having a "disfigurement", thereby attributing a particular discursive construction to her. The woman may have felt labelled by someone else, a doctor with considerable symbolic and actual power, with a medical term. She had not really defined herself and her own bodily experiences through the single term "disfigurement" up until that moment. The term "disfigurement" may have contributed to a feeling of difference from other bodies for the individual. Bodily differences are often recognisable and enforced by others. The surgeon probably needed to use the term to follow medical protocol and appear professional. Being made aware of being different from others was also discussed by many other interviewees in the project. It also showed itself in how they spoke about their use of social media for the purpose of raising awareness of facial disfigurements. "On Instagram, I do more shots of, less shots of, selfies, more shots of my full body" (15). Another female interviewee spoke about whom she followed on Twitter: "I try and follow as many charities, as many charities, but also ones that are appropriate to me erm to support" (I3). Such narratives imply that the individuals' use of so- 
cial media was clearly affected by their subjectivities. Interviewees emphasised a connection between how they used social media, who they followed and their bodily differences. Many also spoke of how they handled responses to their bodily differences online. For example, one interviewee described the Facebook page she had set up:

I made a mistake when I first erm started my page..., I remember just taking a picture of my back and that was it, so all you see was burns and it got quite a lot of negative, yeah and a lot of negativity come from, $\cos ^{\prime}$ I think I had like an open page and I had loads of followers and literally built three and a half thousand friends and fifteen hundred followers but a lot of the followers were literally like from India, from different parts of Asia and they were mainly the ones that they would say, they'd say "pretty" and "slut" so there was kind of, yeah they were putting me down and saying "Eew that's disgusting, that's ugly, put it away, cover up", they were not happy with it, another thing that I've learned is that when I've gone abroad to other countries erm if I show off my scars, they tend to laugh at me, almost like it's a joke and I get that quite a lot. (12)

Another person, who had a cleft lip and palate, initially said that they were not a big part of her identity: "the cleft lip and palate is part of my identity, but it's a small part. It's not the first, like, if you were to ask me to write down ten things about myself, it might not even feature on that list" (I5, lines 537-540). However, as the interview went on, she described her use of Instagram:

I think the biggest thing, so on Instagram, like, occasionally I will see a photo of myself, and I'm like, "Oh that really highlights my cleft." And I'll be like, "Oh, please use the one where it's less visible." Like, or less apparent. So yes, so that's something that Instagram has, kind of, like, the way that I see, the way that I take photos of myself, or that other people take of me, you know, there are angles and there is, but then, again, that's kind of problem that everybody has, I think. Everybody has, like, unflattering photos and angles, and more. So I, yes, like everybody else I'll be, like, "Can you use that one of me please because it looks a bit better than this one?"...So if a photo is taken of me from a, sort of, side angle on this side, my face looks very dented. I'm like, "No!" So yes, so, photos, yes, photo editing and things like that. But, yes, but there are, I think it depends on how you use Instagram as well. Mine is to, kind of, document my life. (15)

The quotes suggest that affective-digital labour played a key role in the participants' social media use. It showed how they brought particular embodied subjectivities to their self-representation online and were then affected by responses from others. Many participants spoke about a pro-active and agentic approach to negotiating their bodily differences on social media. Both of the above quotes signify a heightened self-surveillance as well. The two interviewees emphasised their own responsibilities of maintaining their social media profiles and online images rather than the negative responses from others. The interviewee spoke of the "mistake" when uploading a particular photo that showed too much of her burns. The other participant similarly spoke about her desire to present herself online in a manner that made her bodily difference less apparent. Going back to Hardt and Negri's (2000) definition of affective labour, we can see how the two users spoke about their affective-digital labour in a way that was about relationalities. It was aimed at other users and it seemed that in order to be able to successfully raise awareness, forms of self-representation needed to be conducted in a nuanced manner so that others were not offended. The two quotes exemplify what it means to manage affect online and attempts to create particular affective atmospheres that were characterised by feelings of ease for all involved. This can be further exemplified through another narrative from a woman who spoke about her efforts of raising awareness on social media:

I am doing this all on my own, I mean I had, I've got like the little website which erm I had help with but I am gonna start doing that myself and so a lot of it is done on social media like Instagram, Twitter and Facebook, I've got over 2000 people on my Facebook group and that's still building. I think if it did become a little bit negative l'd definitely look at myself and think what is it I am doing wrong? And I think what I tend to do is just keep it erm not too "happy" happy cos' otherwise people go "Oh that's crap, it can't be like that all the time" but I just always thank people, I always reply to people as well which they seem to like and then they come back with another reply saying "You're great" and yeah I don't know what I am doing but it seems to be working. (12)

What is perhaps most striking about those accounts of social media use is that they implicitly frame it as a form of individualised, labour that comes close to the notion of the entrepreneurial self. Rather than emphasising communal and solidary forms of social media use, the people interviewed all spoke of their solitary efforts. The narratives further demonstrate the usefulness of the Freudian model of affect as a subjective experience. The interviewees spoke of their own bodies and how they were being affected and also affecting others through their embodied subjectivities online. At the same time, their bodies were already affected in the wider social world beyond social media through being laughed at by others, stared at, commented on or questioned. For Freud (1981a), affect is situated at the intersection of the discursive and non-discursive. The discursive narratives reproduced here may be seen as attempts to speak about particular 
affective experiences and ways of being in the world with specific bodily differences. The specific strategies of using social media, which were akin to producing feelings of ease and wellbeing that Hardt and Negri identify as characteristics of affective labour, may thus be seen as attempts to discharge or pre-empt unpleasurable affective experiences so that the affective labour online may be experienced as pleasurable by the interviewees.

Related to this, one interviewee spoke of the positive affectivity associated with the production of a YouTube video which showed her bodily differences:

I released so much and I didn't realise that I would and everything that I spoke about, it was just like erm I've taken this coat off and I am now free like that's exactly how I felt and I went home and I realised that I was a changed person, just from the video and what made it even better was the fact that people started to see it, they started to comment, put it on YouTube and put it on my Facebook page so all my cousins, family, friends they all see it and everybody was telling me what an amazing woman I was and to hear such good feedback and hear such lovely messages it just made me feel so good, so now l've gone from that negative person into this all positive me. (12)

The expression "I released so much" may be seen as an attempt to describe her affective, pleasurable discharge that occurred as a result of uploading the video and the responses she received. They resulted in a feeling of ease for her. This is a distinct example of a pleasurable affective moment whereby feelings of solidarity, support and care resulted in an affective experience which the individual described as making her feel "so good".

\subsection{The Unpleasures of Affective Experiences}

Many participants spoke in detail about the unpleasures and anxieties associated with their labour on social media. Many said they feared being trolled or harassed online, but this only strengthened their goals of raising awareness and making their voices heard. "It [trolling] is at the back of your mind but I try not to think about it too much" (I1). "What's the worst that can happen? Get memed, trolled? They are just a random person on a computer at the end of the day" (I3). "There's the kind of tweet where you just want to just reach through the screen and just slap. So, I do find that with social media sometimes that it can be this cycle where you feel like you have to have the last word and that's not very healthy, but for the most part it's great." (14), as some interviewees remarked. Such narratives can be seen as examples of disaffection (Gibbs, 2002) whereby particular affective experiences are surpassed or left behind through speaking about them and thereby rendering them perhaps less affecting than they may have been in the moment they occurred. Managing this, sometimes tense, relationship of having a disfigurement and being affected by others in a negative way was crucial for the social media labour of the participants. One interviewee, who had missing fingers, also spoke about unpleasurable experiences:

IE: I do get that on tubes, of people, like, taking photos of my hands.

IV: Really?

IE: Yes.

IV: What do you do when that happens?

IE: Well, it's really awkward. I always think that I'm going to do something amazing, you know? I'm going to be, you know, I'm going to say something and I'm going, and I just don't because normally they're...

IV: Well, it's hard to do that.

IE: Well, also because they could be like, I'm not doing that, you know?

IV: They could deny it.

IE: Unless they were right in front of me, like, zooming in, they could pretend they're not doing it. You know, I can see that they're doing it and they're laughing and they're sharing it with their friends online or whatever. (14)

Those quotes show that social media use is an embodied practice which revolves around affective intensities. Those intensities circulate between social media users and social media interfaces. As discussed, social media may provide spaces for particular, pleasurable affective atmospheres to emerge and be managed, but such atmosphere can also be disrupted by other users. Social media labour was thus an ambivalent affair for the participants and resulted in heightened self-monitoring and care of what and how they posted online. Such practices are acts of affective-digital labour because they ultimately aim to create feelings of ease, wellbeing, passion and relationships online, or in short: the perfect product of a self-commodified user. User labour on corporate social media is thus characterised by a sense of affective fragility which both embraced and feared, managed and disrupted periodically.

\section{Conclusion: Towards a Psychoanalytic Theory of Affective-Digital Labour}

It was the goal of this article to introduce a model of affective-digital labour based on Sigmund Freud's works on affect. The field of digital labour has predominantly seen studies from political economy which examine the phenomenon from a structural point of view. There are some studies which have begun to theorise such labour as affective and are interested in exploring the inherent dimensions more (Jarrett, 2015; Pybus, 2013, 2015). There is scope to continue such work, as I have done in this article. Freud conceptualised an affective experience as a subjective state where the body becomes its own speaker (Stein, 1999). For him, affect is fleeting and transitory but can have strong and lasting impressions on the 
individual. This was demonstrated by the interview narratives in which people with facial disfigurements spoke at length about their experience of using social media. Objectively speaking, their use of social media is a form of labour because it contributes to exchange value being generated by social media companies. There was also another dimension which lent itself to theorising the forms of self-presentation as labour because users spoke of it in an almost business-like, entrepreneurial manner. Their use of social media was goal directed to raise awareness of their own bodies. I discussed various examples that highlight pleasurable or unpleasurable affective experiences of the interviewees. They had difficulties fully translating such embodied experiences into words. There is always a dimension that remains unrepresentable. It cannot be fully described through language. Through their labour, interviewees were keen to create particular affective atmospheres on social media. Atmospheres that were about creating and sustaining feelings of ease, well-being and passion for all involved users. This form of social media engagement shows how users are agentic and empowered as well as attacked and disrupted by others on social media. Their representation gives them some form of power but this power comes at a cost. It is exploited by social media companies and affected by other users when they attack or make fun of them. This results in a form of self-monitoring where users try to navigate between presenting themselves, but doing so in a manner that maintained a pleasurable affective atmosphere.

I have thus put forward a distinct model of affective labour, which enriches the one developed by Hardt and Negri as part of their work on immaterial labour $(2000,2004)$. A psychoanalytic model of affective-digital labour on social media takes account of embodied forms of use which are contradictory, messy and in tension with discourse. While I have arguably offered an illustration of affective labour through a particular angle (i.e., through a discussion of individuals with visible facial differences), it can nonetheless point to more general dimensions of labour on social media. The professional use in which many individuals use social media platforms today is marked by particular, (un)pleasurable affective experiences in relation to others. It is also about managing affective atmospheres online through maintaining particular relationalities (e.g., through posting in a certain way, liking another's post, etc.). This labour is difficult to fully describe through language alone because it is both based on individuals' particular embodied subjectivities as well as conducted in a bodily manner online. Such a concept allows for inherent, rather than only structural, aspects of affective-digital labour to be theorised and researched.

\section{Conflict of Interests}

The author declares no conflict of interests.

\section{References}

Ahmed, S. (2014). Cultural politics of emotion. Edinburgh: Edinburgh University Press.

Andrejevic, M. (2011). Surveillance and alienation in the online economy. Surveillance \& Society, 8(3), 278-287.

Andrejevic, M. (2014). Alienation's returns. In C. Fuchs, \& M. Sandoval (Eds.), Critique, social media and the information society (pp. 179-190). New York, NY: Routledge.

Cho, A. (2015). Queer reverb: Tumblr, affect, time. In K. Hillis, S. Paasonen, \& M. Petit (Eds.), Networked affect (pp. 43-58). Cambridge, MA: MIT Press.

Clough, P. T. (2013). The digital, labor, and measure beyond biopolitics. In S. Trebor (Ed.), Digital labor: The Internet as playground and factory (pp. 112-126). London: Routledge.

Clough, P. T., Goldberg, G., Schiff, R., Weeks, A., \& Willse, C. (2007). Notes towards a theory of affect-itself. Ephemera: Theory and Politics in Organization, 7(1), 60-77.

Comor, E. (2010). Digital prosumption and alienation. Ephemera: Theory \& Politics in Organization, 10(3), 439-454.

Coté, M., \& Pybus, J. (2011). Learning to immaterial labour 2.0: Facebook and social networks. M. Peters \& E. Bulut (Eds), Cognitive capitalism, education and digital labor (pp. 169-194). New York, NY: Peter Lang.

Dean, J. (2014). Communicative capitalism and class struggle. Spheres: Journal for Digital Cultures, 1, 1-16. Retrieved from http://spheres-journal.org/ communicative-capitalism-and-class-struggle

Ekman, M. (2012). Understanding accumulation: The relevance of Marx's theory of primitive accumulation in media and communication studies. TripleC: Communication, Capitalism \& Critique-Journal for a Global Sustainable Information Society, 10(2), 156-170.

Fisher, E. (2012). How less alienation creates more exploitation? Audience labour on social network sites. TripleC: Communication, Capitalism \& Critique-Journal for a Global Sustainable Information Society, 10(2), 171-183.

Freud, S. (1981a). Sketches for the "preliminary communication" of 1893. In The standard edition of the complete psychological works of Sigmund Freud (Vol. 1) (pp. 147-151). London: The Hogarth Press and the Institute of Psycho-Analysis.

Freud, S. (1981b). The neuro-psychoses of defence. In The standard edition of the complete psychological works of Sigmund Freud (Vol. 3) (pp. 43-62). London: The Hogarth Press and the Institute of PsychoAnalysis.

Freud, S. (1981c). The interpretation of dreams. The standard edition of the complete psychological works of Sigmund Freud (Vol. 5). London: The Hogarth Press and the Institute of Psycho-Analysis. 
Fuchs, C. (2008). Internet and society: Social theory in the information age. New York, NY: Routledge.

Fuchs, C. (2010). Labor in informational capitalism and on the Internet. The Information Society, 26(3), 179-196.

Fuchs, C. (2012). Dallas Smythe today-The audience commodity, the digital labour debate, Marxist political economy and critical theory. Prolegomena to a digital labour theory of value. TripleC: Communication, Capitalism \& Critique-Journal for a Global Sustainable Information Society, 10(2), 692-740.

Fuchs, C. (2014). Digital labour and Karl Marx. London: Routledge.

Fuchs, C., \& Sevignani, S. (2013). What is digital labour? What is digital work? What's their difference? And why do these questions matter for understanding social media? TripleC: Communication, Capitalism \& Critique-Journal for a Global Sustainable Information Society, 11(2), 237-293.

Garde-Hansen, J., \& Gorton, K. (2013). Emotion online: Theorizing affect on the Internet. Basingstoke: Palgrave Macmillan.

Garrisi, D., \& Johanssen, J. (2018). Competing narratives in framing disability in the UK media: A comparative analysis of journalistic representations of facial disfigurement versus practices of self-representations online. JOMEC Journal, 12, 128-144. Retrieved from https://jomec.cardiffuniversitypress.org/articles /abstract/10.18573/jomec.172

Gibbs, A. (2002). Disaffected. Continuum: Journal of Media \& Cultural Studies, 16(3), 335-341.

Green, A. (1999). The fabric of affect in the psychoanalytic discourse. London: Routledge.

Hardt, M., \& Negri, A. (2000). Empire. Cambridge, MA: Harvard University Press.

Hardt, M., \& Negri, A. (2004). Multitude. New York, NY: Penguin.

Hearn, A. (2010). Reality television, The Hills and the limits of the immaterial labour thesis TripleC: Communication, Capitalism \& Critique-Journal for a Global Sustainable Information Society, 8(1), 60-76.

Hochschild, A. R. (1983). The managed heart: Commercialization of human feeling. London: University of California Press.

Jarrett, K. (2015). Feminism, labour and digital media: The digital housewife. New York, NY: Routledge.

Johanssen, J. (2016). Not belonging to one's self: Af- fect on Facebook's site governance page. International Journal of Cultural Studies. Doi: 10.1177/ 1367877916666116

Johanssen, J. (in press). Psychoanalysis and digital culture: Audiences, social media, and big data. London: Routledge.

Johanssen, J., \& Garrisi, D. (2017). "I am burning, I am burning." Affect, acid attacks and British tabloid newspapers. Journalism Studies. Doi: 10.1080/ 1461670X.2017.1389294

Karatzogianni, A., \& Kuntsman, A. (Eds.). (2012). Digital cultures and the politics of emotions. Feelings, affect and technological change. Basingstoke: Palgrave Macmillan.

Lanoix, M. (2013). Labor as embodied practice: The lessons of care work. Hypatia, 28(1), 85-100.

Lazzarato, M. (1996). Immaterial labor. In P. Virno \& A. Negri (Eds.), Radical thought in Italy: A potential politics (pp. 133-147). Minneapolis, MN, and London: University of Minnesota Press.

Marx, K. (1976). Capital: A critique of political economy (Volume 1). Harmondsworth: Penguin Books.

Paasonen, S., Hillis, K., \& Petit, M. (2015). Introduction: Networks of transmission: Intensity, sensation, value. In: K. Hillis, S. Paasonen, \& M. Petit (Eds.), Networked affect (pp. 1-24). Cambridge, MA: MIT Press.

Pybus, J. (2013). Social networks and cultural workers: Towards an archive for the prosumer. Journal of Cultural Economy, 6(2), 137-152.

Pybus, J. (2015). Accumulating affect: Social networks and their archives of feelings. K. Hillis, S. Paasonen, \& M. Petit (Eds.), Networked Affect (pp. 234-249). Cambridge, MA: MIT Press.

Sampson, T. (2012). Virality: Contagion theory in the age of networks. Minneapolis, MN: University of Minnesota Press.

Smythe, D. (1981). Dependency road. Norwood, NJ: Ablex.

Stein, R. (1999). Psychoanalytic theories of affect. London: Karnac.

Terranova, T. (2000). Free labor: Producing culture for the digital economy. Social Text, 18(2), 33-58.

Tzankova, V. (2015). Affective politics or political affection: Online sexuality in Turkey. In K. Hillis, S. Paasonen, \& M. Petit (Eds.), Networked affect (pp. 59-74). Cambridge, MA: MIT Press.

\section{About the Author}

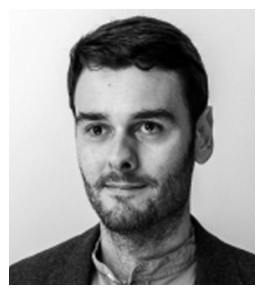

Jacob Johanssen is Senior Lecturer in the Communication and Media Research Institute (CAMRI), University of Westminster, UK. His research interests include audience research, social media, digital labour, psychoanalysis and the media, affect theory, psychosocial studies, and critical theory. His monograph Psychoanalysis and Digital Culture: Audiences, Social Media, and Big Data is forthcoming with Routledge. 